\title{
Effect of cattle urine vs $4 \%$ urea treated rice straw feeding on milk yield, straw intake and dung output in Jersey crossbred cows in the hills of Nepal
}

\author{
RK Kadariya 1, PR English 2, JA Roden 2, DP Rasali 1 \\ 'Lumle Agricultural Research Centre (LARC), PO Box 1, Pokhara, Kaski, Nepal; \\ zUniversity of Aberdeen, Department of Agriculture, 581 King Street, Aberdeen, UK
}

The rice straw plays a dominant role in feeding the large ruminants in Nepal. It is considered as a basal diet and makes up a large proportion $(60 \%)$ of the cattle and buffalo feed (Dhaubhadel et al, 1991, LARC Seminar Paper 28). Rice straw is fed throughout the year. However, it is fed mostly from November to June (hungry-gap period) when herbage growth is minimum.

Urea treatment of straw and its use as animal feed is practised to some extent on government farms in Nepal. Whilst, at the farmer's level the use of urea as a source of non-protein nitrogen (NPN) is still in its initial stages due to a variety of constraints. A trial was conducted at LARC (1650 $\mathrm{m}$ asl) between February and March 1992 to investigate whether cattle urine (T1) could be a possible source of non protein nitrogen to replace urea (T2). The urine (T1) was collected and mixed with rice straw in a ratio of 1:1 and ensiled in a pit for 4 weeks. Similarly $4 \%$ urea solution (T2) was sprayed on rice straw and it was ensiled in a pit for 4 weeks before feeding to Jersey crossbred cattle. The urine treated straw (T1) and urea straw (T2) were offered ad libitum for a period of three weeks.

The mean daily milk yield, straw intake and dung output were recorded for three weeks (first week, W1 ; second week, W2 ; third week, W3) from two groups each of 3 crossbred cows. Statistical analysis (one-way analysis of variance) revealed no significant difference $(P>0.05)$ in mean daily milk yield, straw intake and dung output between the two groups (T1 and T2).

In conclusion, cattle urine could be used to replace urea to supplement NPN in ruminant diets. It may be argued, however, that a more substantial study may lead to significant differences in the effectiveness of the urine and urea as a source for the treatment of rice straw. This findings provide a stimulus to further investigation on urine as a cheap alternative to purchase urea. Moreover, the possibility of using urine as a urea substitute needs more attention not only in the technical aspects but also in the logistics and its social acceptance.

\begin{tabular}{lcccc} 
Parameters & Feed & W1 & W2 & W3 \\
\hline Milk yield/day/cow $(\mathrm{kg})$ & T1 & 4.51 & 3.57 & 3.38 \\
Milk yield/day/cow $(\mathrm{kg})$ & T2 & 3.61 & 2.29 & 2.67 \\
Straw intake/day/cow $(\mathrm{kg})$ & T1 & 7.63 & 10.10 & 9.15 \\
Straw intake/day/cow $(\mathrm{kg})$ & T2 & 8.35 & 8.23 & 9.13 \\
Dung output/day/cow $(\mathrm{kg})$ & T1 & 18.24 & 19.81 & 21.24 \\
Dung output/day/cow $(\mathrm{kg})$ & T2 & 21.06 & 21.87 & 23.21 \\
\hline
\end{tabular}

